\title{
OPEN Multiple phases of human occupation in Southeast Arabia between 210,000 and 120,000 years ago
}

\author{
K. Bretzke ${ }^{1,2,3 凶}$, F. Preusser ${ }^{4}$, S. Jasim ${ }^{5}$, C. Miller ${ }^{6,7}$, G. Preston ${ }^{8}$, K. Raith ${ }^{8}$, S. J. Underdown ${ }^{8,9}$,
} A. Parton ${ }^{8,10}$ \& A. G. Parker ${ }^{8,11}$

Changing climatic conditions are thought to be a major control of human presence in Arabia during the Paleolithic. Whilst the Pleistocene archaeological record shows that periods of increased monsoon rainfall attracted human occupation and led to increased population densities, the impact of arid conditions on human populations in Arabia remains largely speculative. Here, we present data from Jebel Faya in Southeast (SE) Arabia, which document four periods of human occupation between $c$. 210,000 and 120,000 years ago. The Jebel Faya record indicates that human occupation of SE Arabia was more regular and not exclusively linked to major humid periods. Our data show that brief phases of increased rainfall additionally enabled human settlement in the Faya region. These results imply that the mosaic environments in SE Arabia have likely formed a population refugia at the end of the Middle and the beginning of the Late Pleistocene.

Presently a vast dry land, human occupation of Arabia is thought to be closely linked to climate change and limited to periods of increased precipitation ${ }^{1-3}$. Moisture is derived by both Mediterranean cyclones and through the African and Indian monsoon systems, in particular in the southern and western part of the peninsula ${ }^{4-6}$. The strength of the monsoon has varied through time due to orbital forcing ${ }^{7,8}$, with northern hemisphere glacial periods accompanied by low latitude aridity. Such periods of aridity are expected to represent hostile environments that formed an obstacle for human occupation of Arabia ${ }^{9-11}$. Increased precipitation occurred during past interglacials and interstadial periods as known from the mid-latitudes ${ }^{9,12}$, triggering the expansion of vegetation and increased faunal diversity in landscapes featuring lakes and perennial rivers in Arabia ${ }^{13-15}$. Due to the favorable living conditions during such periods, they are thought to be the most likely periods of intensified Paleolithic settlement in Arabia ${ }^{14,16-18}$.

The Arabian archaeological record supports the view of human occupation linked to periods of increased rainfall ${ }^{19}$. This is best exemplified by the coincidence of peak humid conditions between $c .130$ and $75 \mathrm{ka}$ and the well-developed archaeological records from many parts of the peninsula including Saudi Arabia ${ }^{20-22}$, the United Arab Emirates ${ }^{23}$ and Oman ${ }^{24}$. Additional evidence for human occupation of Arabia during wetter periods are known from the timeframe between 240 and $190 \mathrm{ka}$ and between $c .60$ and $50 \mathrm{ka}$ and include sites in Saudi Arabia $^{25-27}$, Yemen $^{28}$ and $\mathrm{Oman}^{29}$. The archaeological record securely predating c. $240 \mathrm{ka}$ is not well developed,

\footnotetext{
${ }^{1}$ Department of Early Prehistory and Quaternary Ecology, University of Tübingen, Burgsteige 11, 72070 Tübingen, Germany. ${ }^{2}$ The Role of Culture in Early Expansions of Humans Project, Heidelberg Academy of Science and Humanities, Heidelberg, Germany. ${ }^{3}$ Seminar for Prehistoric and Protohistoric Archaeology, University of Jena, Löbdergraben 24a, 07743 Jena, Germany. ${ }^{4}$ Institute of Earth and Environmental Sciences, University of Freiburg, Albertstr. 23b, 79104 Freiburg, Germany. ${ }^{5}$ Sharjah Archaeology Authority, Government of Sharjah, Sharjah, United Arab Emirates. ${ }^{6}$ Institute for Archaeological Sciences \& Senckenberg Centre for Human Evolution and Palaeoenvironment, University of Tübingen, Tübingen, Germany. ${ }^{7}$ SFF Centre for Early Sapiens Behaviour (SapienCE), University of Bergen, Øysteinsgate 3, Post Box 7805, 5020 Bergen, Norway. ${ }^{8}$ Human Origins and Palaeoenvironments Research Group, School of Social Sciences, Oxford Brookes University, Gipsy Lane, Oxford OX3 OBP, UK. ${ }^{9}$ Center for Microbial Ecology and Genomics, Department of Biochemistry, Genetics and Microbiology, University of Pretoria, Hatfield, South Africa. ${ }^{10}$ Mansfield College, University of Oxford, Mansfield Road, Oxford OX1 3TF, UK. ${ }^{11}$ ARC Centre of Excellence for Australian Biodiversity and Heritage, University of Wollongong, Wollongong, Australia. ${ }^{\boxplus}$ email: knut.bretzke@uni-jena.de
} 


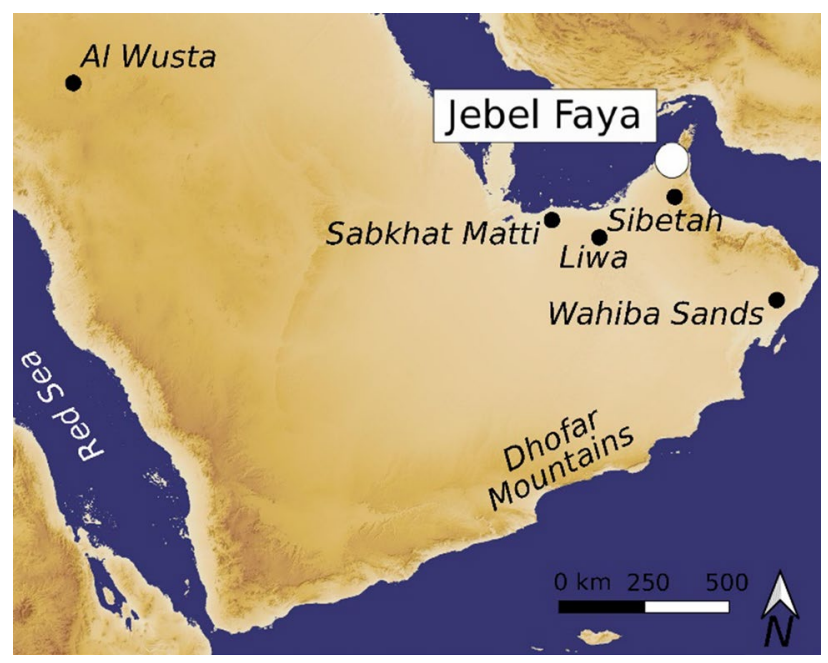

Figure 1. Map showing the location of Jebel Faya in Southeast Arabia and other sites and geographic regions mentioned in the text. Figure produced using QGIS 3.4. (https://qgis.org) and Inkscape 1.0 (URL: https://inksc ape.org).

but evidence from the Nefud (Saudi Arabia) points towards climate driven human occupation between 500 and $55 \mathrm{ka}^{19,30}$.

Supposedly arid periods between $c .190 \mathrm{ka}$ and $130 \mathrm{ka}, c .75 \mathrm{ka}$ and $60 \mathrm{ka}$ and c. $29 \mathrm{ka}$ and $12 \mathrm{ka}$ provide no evidence for human occupation of Arabia to date. Towards the end of the Pleistocene, the observed pattern of human occupation linked to wetter periods changes with sites from Saudi Arabia ${ }^{31}$ and Oman ${ }^{32}$ known to fall into the Pleistocene to Holocene transition at c. $12 \mathrm{ka}$.

Given available archaeological and paleoenvironmental records, linking increased humidity and increased human demography in Arabia is plausible. Due to the lack of data, the opposite, how increasing aridity affected human populations in Pleistocene Arabia, remains largely speculative. Researchers argue on the one hand that the lack of archaeological evidence for human occupation of Arabia in dry periods is linked to pan-Arabian extinctions and the abandonment of settlement in Arabia ${ }^{19}$. While other researchers argue that desiccation led to the contraction of human populations into refugia such as the Gulf basin region, the Dhofar Mountains and adjacent littoral zone as well as the Red Sea coastal plain ${ }^{33}$. Both explanations are mainly based on untested ecological hypotheses. Fossil and artifactual evidence are difficult to record, given large parts of the refugial zones are today below water, while current paleoclimatic records fail to adequately reflect the complexity and heterogeneity of the contemporary Arabian landscape.

To study the impact of arid conditions on Paleolithic human populations in Arabia, long and securely dated archaeological sequences are required. Sites providing such characteristics are rare. One such place is Jebel Faya in the Emirate of Sharjah, United Arab Emirates (Figs. 1, S1), where a Paleolithic sequence with four archaeological assemblages A-D was excavated in front of a rock shelter ${ }^{23}$. While assemblage D, the lowermost archaeological layer of this terrace sequence, remained undated, the oldest age of around $125 \mathrm{ka}$ was determined for Assemblage $\mathrm{C}^{23}$. Assemblage A from the top of the Paleolithic sequence on the terrace was dated to about $40 \mathrm{ka}^{23}$. Recent field work at Jebel Faya focused on the sequence excavated within the rock shelter area. Excavations exposed a $c$. $3 \mathrm{~m}$ deep sequence with seven archaeological layers (AHs I-VII). Researchers were able to link the rock shelter sequence stratigraphically to the terrace sequence ${ }^{34}$. This shows that the dated Assemblages $\mathrm{C}$ and $\mathrm{A}$ from the terrace correlate with AHs VI and IV from the rock shelter. One key characteristic of the rock shelter sequence, however, is that it extends the known archaeological stratigraphy from previously unknown Middle Pleistocene artifacts (Figs. 2, S2). Here, we present new archaeological, chronological and sedimentological data from Jebel Faya that cover the Middle to Late Pleistocene transition.

\section{Results}

Excavations of the rock shelter (see methods and supplement for details) led to the recovery of an intact sequence of seven archaeological horizons (AHs). We focus here on the lower half of the Faya rock shelter sequence with AHs VII, VI and V (Fig. 2). In general, the archaeological assemblages from AHs VII to V feature a typical mix of Middle Paleolithic technologies and tool types (Fig. 3, Tables S1-S3).

The oldest archaeological layer from the base of the sequence is AH VII, which provides a lithic artifact assemblage $(\mathrm{n}=301)$ that shows evidence for flake production from centripetal and unidirectional Levallois cores (Fig. 3, Table S3). Faceting of striking platforms and a bifacial component are additional technological features observed in AH VII (see Table S3 for details). The tool assemblage is dominated by side scrapers and denticulated artifacts but points and bifacially retouched artifacts do also occur (Fig. 3). Optically Stimulated Luminescence (OSL) dating of two sediment samples (FAYA-38S-OSL5: $172 \pm 10 \mathrm{ka}$, FAYA-38S-OSL6: $172 \pm 18 \mathrm{ka}$ ) provide for AH VII a mean burial age of $172 \pm 9 \mathrm{ka}$ (Table S4). 


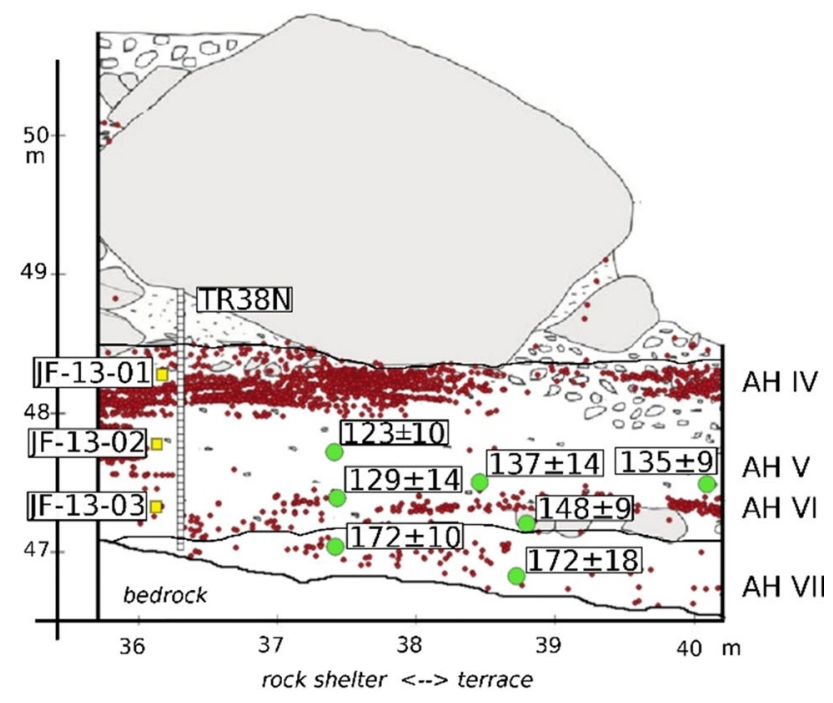

Figure 2. Northern profile of trench 38 at Jebel Faya showing the location of the lithic artifacts from AHs VII-IV (red dots), the location and results of the OSL samples presented here (green circles) as well as the samples for the sedimentological (white squares) and micromorphological study (yellow squares).
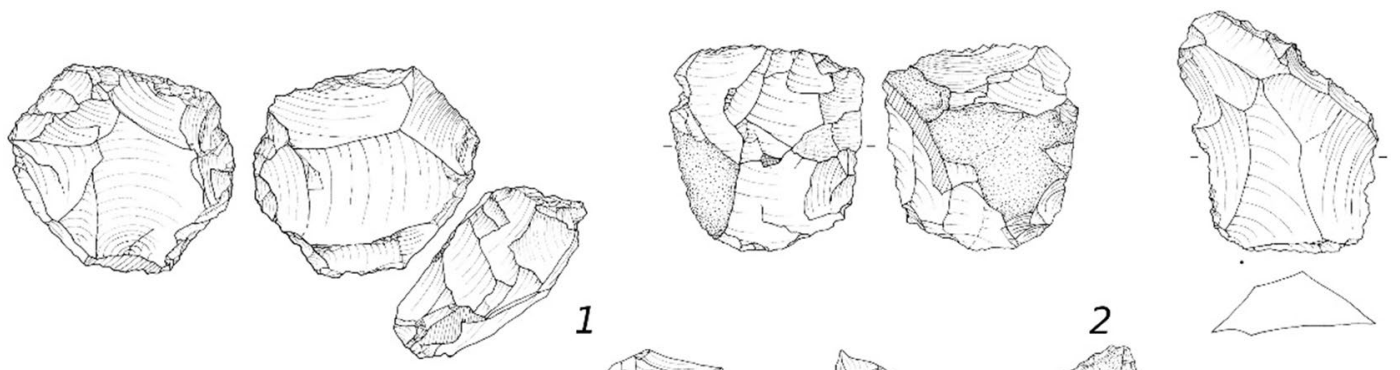
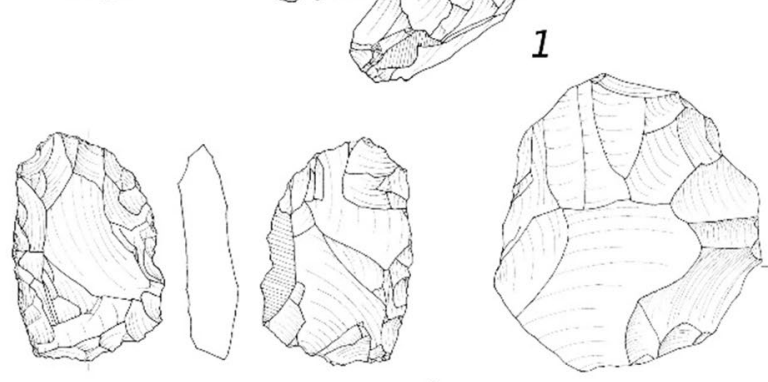

4
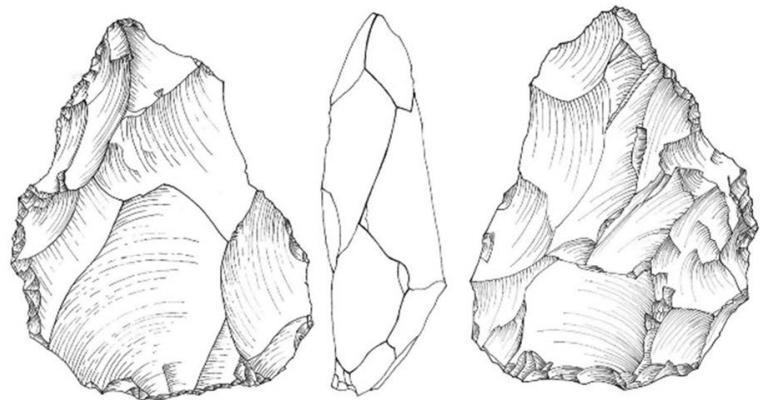

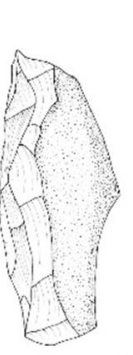

5

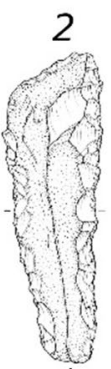

$\Delta 6$

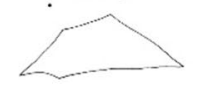

\section{$3 \mathrm{~cm}$}
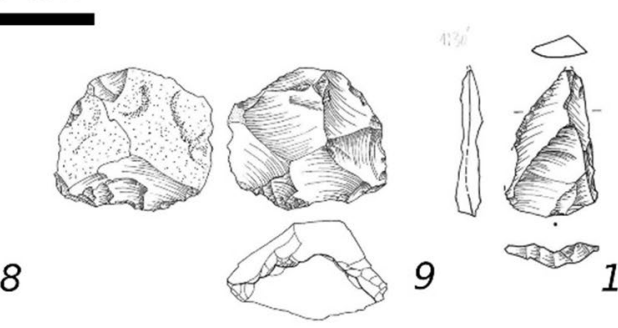

Figure 3. Examples of stone artifacts from AH V (1-3), AH VI (4-7) and AH VII (8-10). (1) inversely retouched scraper, (2) unidirectional Levallois core, (3) sidescraper, (4) bifacial artifact, (5) centripetal Levallois core, (6) retouched blade, (7) point, (8) bifacial artifact, (9) centripetal Levallois core, (10) point.

About $20 \mathrm{~cm}$ above AH VII, the next younger archaeological layer AH VI provides an assemblage of lithic artifacts $(\mathrm{n}=477)$ dominated by centripetal and unidirectional Levallois reduction accompanied by bifacial reduction and blade production (Table S2, S3). The tool assemblage includes bifacial pieces, side scrapers, and denticulated flakes (Fig. 3). OSL sesults from within layer AH VI (FAYA-38S-OSL7: $129 \pm 14$ ka, FAYA-38SOSL 4: $137 \pm 14 \mathrm{ka}$, FAYA19: $135 \pm 9 \mathrm{ka}$ ) reveal a mean depositional age of $134 \pm 7 \mathrm{ka}$ and an age of $148 \pm 9 \mathrm{ka}$ 
(FAYA-38S-OSL8) for the archaeologically sterile layer below. Furthermore, $10 \mathrm{~cm}$ above AH VI, a layer of lithic artifacts $(n=755)$ forms AH V. The lithic assemblage provides evidence for flake production from flat cores featuring convergent and orthogonal scars as well as from unidirectional Levallois cores (Table S3). An increased proportion of lithic artifacts featuring converging edges is evident in this layer, but there are no indications for true converging flaking technologies (see SI for details $a^{3} d^{34}$ ). Scrapers and denticulates form the majority of the tool assemblage accompanied by an increased number of pointed artefacts (Fig. 3, Table S2). The OSL sample from $\mathrm{AH} V$ produced a result of $123 \pm 10 \mathrm{ka}$ (FAYA-38S-OSL3).

Sedimentological and stratigraphic characteristics have been considered during excavation (see supplement). To gain more detailed insight into site taphonomy additional analyses were conducted in the $2 \mathrm{~m}$ thick section TR38N (Fig. S3) and from three micromorphology samples (JF-13-1, JF-13-2, JF-13-3). These samples are located under a massive rock shelter roof collapse deposit, which contains the lower part of the Faya rock shelter sequence comprising archaeological layers AH VII to AH IV (Fig. 2). Our results show that occupation layers tend to be dominated by sediments with an exogenic rock shelter component and an aeolian component (AD facies, see methods). In contrast, the archaeologically sterile layers tend to be dominated by facies originating from infiltration processes (facies FO) that commonly contain debris and rock fragments derived from weathering into finer grained material ${ }^{35}$. Further it has to be noted that host limestone bedrock comprises $<1 \%$ sand, and that it is emplaced due to gravity and rockfall processes. Beds dominated by rockfall debris (facies $\mathrm{RD}$ ) also occur. They often show large blocks up to $50 \mathrm{~cm}$ derived from the collapse of part of the ceiling of the shelter with interstitial matrix derived from infiltration processes. Micromorphological analysis of the Faya rock shelter sequence confirms the interpretation of a largely aeolian source of sediment for the fine fraction of AH V and IV. Post-depositional alteration of the deposits is present, although weak. Evidence for localized carbonate cementation in the form of interstitial growths of micrite is present, as is localized iron and manganese staining of the fine fraction. There are also rare, infilled burrows, but despite a general absence of sedimentary structures, bioturbation does not appear to have significantly impacted the deposits.

Additional chronometric data has been collected from the lowermost archaeological layer in the Faya terrace sequence (Fig. S2). Assemblage D has previously not been dated. The lithic assemblage from this layer is relatively small $(n=177)$ and hence difficult to interpret beyond the notion of human presence at the site. Our OSL sample (FAYA-19N-OSL9) from sediments containing assemblage D indicates a burial age of the lithic assemblage of $212 \pm 19 \mathrm{ka}$.

\section{Discussion}

The lower part of the Jebel Faya rock shelter record presented contains a sequence of Middle Paleolithic assemblages, which show human presence at about $210 \mathrm{ka}, 170 \mathrm{ka}$, and between 135 and $120 \mathrm{ka}$. These new data deepens the occupation history of the site substantially and identify previously unknown phases of human occupation in Southeast (SE) Arabia pre-dating Marine Isotope Stage 5 (c. 130-75 ka). Our data reveals that human occupation was more regular and not restricted to prolonged periods of increased rainfall. Instead, it indicates that brief wet spells may have played an important role on shaping human presence in SE Arabia.

OSL results from the bottom of the sequence place AH VII firmly into early MIS 6. Dating of AHs VI and V shows that the lithic assemblages have been most likely discarded at the beginning of MIS 5 . While saying this, our results do not exclude the possibility of AH VI representing human occupation at the end of MIS 6. Given a c. 25 ka year gap between AHs VII and VI the typological and technological similarities of the lithic assemblages are striking. Rather simple tool types and minor shifts in the preference for the tool production systems suggest that no sophisticated adaptation in the lithic culture was required to survive in the ecological settings of the Faya region during the late Middle and early Late Pleistocene.

The new chronometric data from the Faya rock shelter sequence corresponds well with previous results presented for Faya ${ }^{23}$. Age estimations for AH VI (mean depositional age: 127-141 ka) fall within the range of the stratigraphically linked Assemblage C, for which Armitage et al..$^{23}$ provide age estimations of $111-143 \mathrm{ka}$ and 113-133 ka. While stratigraphic order would dictate that AH V is younger than AH VI, our OSL results indicate that $\mathrm{AH} \mathrm{V}$ was deposited between 113 and $133 \mathrm{ka}$ ago. The age of AHs VI and V are thus statistically indistinguishable. Assemblage B, overlaying Assemblage $\mathrm{C}$ in the terrace excavation, is stratigraphically linked to AH V. Since Assemblage B is undated, it provides no information that could help regarding the question of the chronological gap between AHs VI and V. Both excavations (terrace and rock shelter), however, similarly described an only small depositional buffer between the two archaeological layers of about $10 \mathrm{~cm}$. It could thus be assumed that the chronological gap between AH VI and V as well as Assemblage C and B is relatively short. Age estimates of about 139-157 ka for sediments below AH VI and of 163-181 ka (mean depositional age) for $\mathrm{AH}$ VII indicate stratigraphic integrity of the rock shelter sequence and the robustness of the presented chronological framework.

The Pleistocene human occupation at Jebel Faya has previously been thought to be restricted to long periods of increased rainfall, in particular during MIS $5^{23,36}$. This conclusion is largely drawn indirectly from speleothem records from Hoti Cave in the Hajar Mountains and Al-Mukalla Cave in Yemen, which demonstrate speleothem growth in MIS 7 and MIS 5 $5^{37,38}$. The onset and termination of MIS 6 are recorded in the Hoti and Al Mukalla speleothem records, but they do not extend into MIS 6 . Given that the formation of speleothems is determined by rainfall, it has been suggested that precipitation in excess of $350 \mathrm{~mm}$ per year is required to initiate growth (e.g., ${ }^{38,39}$ ). Paleoenvironmental evidence from SE Arabia indicates that a relatively small amount of rainfall was sufficient to activate alluvial fans and generate fluvial channel flow in MIS $6^{40,41}$ but was insufficient for speleothem growth. The Jebel Faya records testify that local geographic and environmental conditions can support a more frequent human occupation in SE Arabia beyond global peak interglacial periods. This reflects the importance 


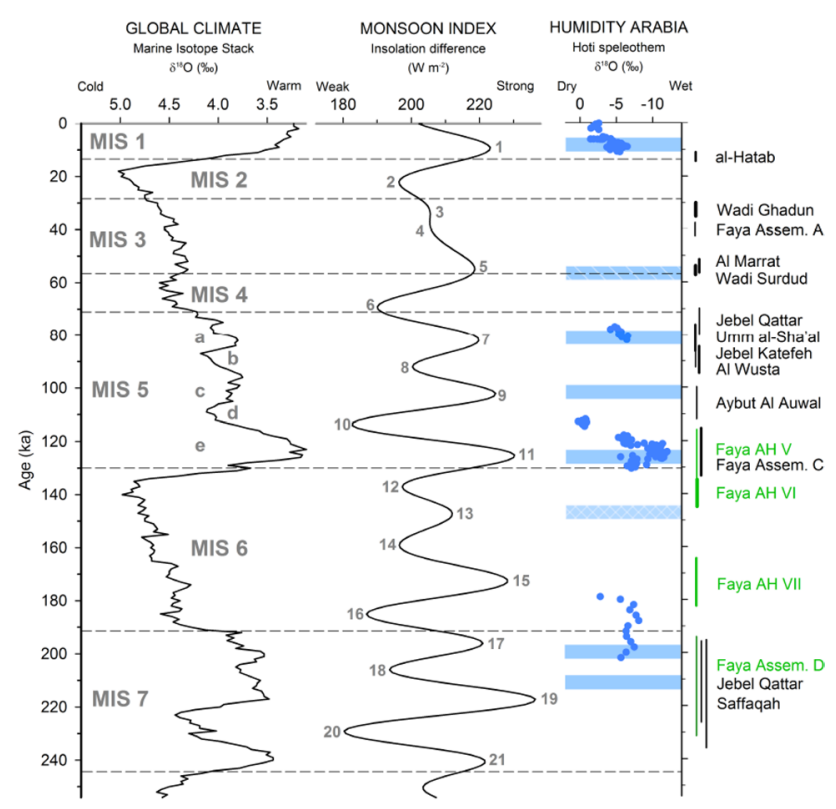

Figure 4. Marine isotope stack as proxy of global climate ${ }^{56}$, the Monsoon Index ${ }^{43}$, speleothem isotope data (blue circles ${ }^{37}$ ) as well as phases of lake formation (blue bars ${ }^{4,6,11,13-15,41,45,47}$ ) as representation of regional environmental conditions in Arabia. Note the co-occurrence of odd numbered Monsoon Index Peaks (MIP) and the archaeological record. Al-Hatab ${ }^{32}$, Wadi Ghadun ${ }^{29}$, Faya Assemblage A $+\mathrm{C}^{23}, \mathrm{Al} \mathrm{Marrat}{ }^{57}$, Wadi Surdud $^{28}$, Jebel Qattar + Jebel Katefeh ${ }^{25}$, Umm al-Sha'al ${ }^{27}$, Al-Wusta $^{20}$, Aybut Al Auwal ${ }^{24}$, Faya AH V-VII + Faya Assemblage D (this paper), Saffaqah ${ }^{26}$.

of producing spatially finer scales of analyses, instead of linking local archaeological records with global climate proxies (e.g., ${ }^{2,42}$ ).

The traditional approach would contextualize the Faya archaeological record with MIS 7, 6 and 5. However, the link between global marine isotope records and regional climates is not straightforward and confirming this link with local records is difficult, given environmental evidence is poorly constrained and age control is often problematic. We argue that the Amero-Eurocentric (glacial vs. interglacial) view on the climatic evolution in Arabia does not fit well with the evidence that has been collected in the field over the past 20 years. Instead of using global marine data, we see more promise in a regional climate approach. In the absence of better alternatives at present, we suggest using the Indian Ocean Monsoon (IOM) Index to model the timing of favorable conditions for human occupation in Arabia. The IOM Index reflects precessionally-driven changes in monsoon intensity, based on latitudinal insolation differences ${ }^{7,43}$. This theoretical approach has been confirmed by field evidence, showing that increased precipitation in Arabia corresponds with maxima in the monsoon intensity ${ }^{17,44,45}$. The timing and frequency of the Monsoon Index Peaks (MIP) increases the chronological resolution for some parts of the Middle to Late Pleistocene history compared to the $c .100$ ka eccentricity driven periodicity of the prevailing glacial-interglacial model (Fig. 4). The chronology of empirical evidence for human occupation in Arabia corresponds well with odd numbered MIPs (Fig. 4), which represent increased insolation driven monsoon intensity as a result of greater seasonality and increased pressure gradients across the Indian Ocean. The correlation of archaeological evidence and MIPs can be demonstrated for the last $130 \mathrm{ka}$ (Fig. 4). However, this link is currently difficult to assess for the Middle Pleistocene to date due to the scarcity of archaeological and paleoenvironmental sites in Arabia. The timing of AH VII and Assemblage D provided here, contribute to the filling of these gaps, and indicates that a correlation of human presence and increased monsoon intensity existed also during the Middle Pleistocene.

The IOM Index indicates two phases of increased humidity within MIS 6 (MIPs 15 and 13, see Fig. 4). This shows that emphasizing exclusively arid or hyper-arid conditions for the $c$. 60 ka period of MIS 6 would oversimplify what is a particularly complex situation. This conclusion corresponds with previous claims for brief wet phases in MIS $6^{1,41,46}$. While wet phases have been identified in the otherwise arid MIS 6 , human presence in Arabia during this period was unknown. AH VII now fills this gap and provides evidence for human occupation of SE Arabia in early MIS 6. The deposition of AH VII correlates with MIP 15, which reaches an intensity similar to the range of MIP 11 (Fig. 4). The latter represents MIS 5e, a period where a well-developed paleoenvironmental record shows pronounced and spatially wide-spread favorable conditions, including the development of perennial lakes and rivers ${ }^{13-15,47}$. Given currently available data, it is difficult to determine if conditions during MIP 15 (AH VII) were indeed as favorable as in MIP 11. Given the Faya evidence, however, it is reasonable to conclude that at the very least, climatic conditions and resource availability were sufficient for a human population to survive for some time in SE Arabia during early MIS 6. While AH V correlates well with MIP 11 and AH VI falls into the period of decreasing monsoon intensity following MIP 13, the correlation of Assemblage D with one MIP is not straightforward due to dating uncertainties. It may either be associated with MIP 19 or MIP 17. 
Our archaeological data adds to a growing body of paleoenvironmental evidence that indicates brief phases of increased precipitation occurred during MIS 6. Evidence for increased water availability in the Faya region during MIS 6 comes from U series dating of carbonate precipitates (c. 168-161 ka and c. 146-136 ka) at Jebel Buhais, about $15 \mathrm{~km}$ south of Faya ${ }^{48}$. Elsewhere in SE Arabia, the prospect of increased rainfall during MIS 6 is corroborated by OSL dating of fluvial silts $(c .147 \mathrm{ka})$ at Sabkhat Matti ${ }^{40}$ and interdunal sabkha sediments in the Liwa region of the Rub' al Khali, UAE, dated between 176 and $144 \mathrm{ka}^{49}$. Situated within an alluvial plain that extends $c .500 \mathrm{~km}$ along the western flanks of the Hajar Mountains, alluvial fan sediments from the Al Sibetah site, UAE (Fig. 1) record over $20 \mathrm{~m}$ of sediment accumulation during MIS 6 between 179 and $130 \mathrm{ka}^{41}$. Evidence from $\mathrm{Al}$ Sibetah shows that during this time braided streams surrounded by a vegetated landscape comprising a mix of $\mathrm{C}_{3}$ and $\mathrm{C}_{4}$ grassland types extended more than $20 \mathrm{~km}$ from the mountain front. At the southern end of the Hajar, incipient soil formation within the Al Jabin Unit of the Wahiba Sands region have been dated between $c$. 160 and $140 \mathrm{ka}^{10,50}$. In sum, paleoenvironmental and archaeological records show that MIS 6 in SE Arabia was not a permanently hyper-arid period and human occupation was possible during that time due to increased rainfall and the development of vegetation in brief phases corresponding with at least MIP 15, but also likely MIP 13.

The lower half of the Faya record shows that human populations have occupied SE Arabia more frequently than previously recognized, while the significant chronological gaps between the occupation phases at Jebel Faya indicate repeated re-occupation of the site. Human presence at Faya during a relatively short-lived wet phase such as MIP 15 (AH VII), however, suggests a relatively rapid re-occupation, which would likely be linked to a spatially neighboring source region rather than long distance movements.

Presently SE Arabia is characterised by steep rainfall gradients across a range of coastal, mountainous, desert and gravel plain geomorphic environments, giving rise to a diverse range of biogeographical distributions and centers of endemism. In particular, the Western Hajar Mountains represent one of the richest and most important floristic regions within the Arabian Peninsula, being home to 24 endemic plants species including evergreen communities indicative of relict former xeromorphic woodlands ${ }^{51}$, and three species of freshwater fish found within mountainous wadis and pools ${ }^{52}$. Consequently, we suggest that rainfall increases during MIS 6 would have been sufficient to activate widespread drainage and increase floral and faunal productivity within the Faya region. Our results demonstrate an increased number of periods where inland areas of SE Arabia provided favorable environmental conditions and attracted human occupation.

From where exactly the Faya populations geographically originated remains unknown, but given indications of rapid re-occupation, shared technological characteristics and biogeographic characteristics, we conclude that our results support the idea of a population refugia in SE Arabia at the end of the Middle Pleistocene and the beginning of the Late Pleistocene.

Despite substantial progress over the past decade, the Paleolithic record of Arabia still features significant gaps (Fig. 4). These are most obvious during the supposedly arid MIS 6, 4 and 2. The presented Jebel Faya data now begin filling the early MIS 6 gap. With this, our results question the suitability of the glacial-interglacial demographic model and suggest the application of regionally-resolved climatic and ecological data (see ${ }^{53}$ for a similar conclusion in an African context), alongside data such as the IOM Index for the contextualisation of archaeological records. Given the climatic, ecological and geomorphic heterogeneity of Arabia, we also suggest that the notion of 'windows' is somewhat dichotomous and may be too simplistic a framework for understanding the complexities of ancient demography. Our results demonstrate that improving our understanding of the early prehistory of Arabia and related anthropological research questions requires targeting the identified chronological gaps through continuous interdisciplinary field work. Concluding human absence from presumed climatic and ecological conditions can be misleading. The search for fresh evidence that further fills in gaps in the archaeological record of Arabia may require working in less well studied geographic settings. These recent developments demonstrate that Arabia has not yet disclosed all secrets about its early settlers.

\section{Materials and methods}

Archaeological excavations. Excavations were conducted using quarter meter units within defined trenches. We piece-plotted all lithic artifacts larger than $2 \mathrm{~cm}$ and each bucket of sediment removed from the site using a Leica Total Station. To maximize recovery of small finds we dry screened all buckets at the site through 6 and $3 \mathrm{~mm}$ mesh and floated selected sediment samples at the field lab. To gain more detailed information about site taphonomy and vertical distribution of finds, we defined archaeological (AH) and geological horizons (GH) during excavation. To distinguish GHs and AHs we used Arabic numerals for geological layers and Roman numerals for archaeological layers. Numbers increase from top to bottom. Sediment characteristics were examined using micromorphological methods and sediment studies in the context of sedimentological research (see below). Analysis of the lithic assemblages followed standard procedures.

Chronology. As the sediment consists mainly of coarse material (gravel to blocks), containing little quartz sand required for OSL dating, sampling was carried out at night using red headlights. The light-exposed outer layer of the exposure was first removed and large amounts of sediment were extracted and sieved on-site to remove the coarse fraction. The fine fraction (sand and silt) was transferred into opaque bags. Bulk sediment representing the sample surroundings was sampled at the same time for dosimetric measurements (high-resolution gamma spectrometry). In the laboratory, the quartz fraction $(100-150 \mu \mathrm{m})$ was extracted and equivalent dose $\left(D_{e}\right)$ was determined using the standardised growth curve single-aliquot regenerative dose approach ( $1 \mathrm{~mm}$ aliquots). Most samples show a moderate spread of De values which calls for the application of different so-called age models (see supplemental material for details). 
Sediment analyses. Sediment samples were collected from the open trench face (Fig. 2) in zip lock bags. Loss-on-ignition (LOI) analyses followed the method described by Heiri et al. ${ }^{54}$. Results are reported as percentages of the dry weight. To determine grain size, samples of air-dried sediment $<2 \mathrm{~mm}$ were gently disaggregated in deionized water with $5 \%$ Calgon (Sodium hexametaphosphate) and analyzed using a Malvern Mastersizer 2000. Grain size statistics are based on the logarithmic graphical measures of the (original) Folk and Ward ${ }^{55}$ method for sorting, skewness and kurtosis. The mean particle size calculations are based on the modified Udden-Wentworth scale and are reported in microns $(\mu \mathrm{m})$. Geochemical analysis was conducted using an Olympus Vanta pXRF.

Received: 17 May 2021; Accepted: 13 January 2022

Published online: 31 January 2022

\section{References}

1. Groucutt, H. S. \& Petraglia, M. D. The prehistory of the Arabian Peninsula: Deserts, dispersals, and demography. Evol. Anthropol. 21, 113-125 (2012).

2. Bretzke, K. \& Conard, N. J. Not just a crossroad: Population dynamics and changing material culture in Southwestern Asia during the late pleistocene. Curr. Anthropol. 58, S449-S462 (2017).

3. Petraglia, M. D. et al. Human responses to climate and ecosystem change in ancient Arabia. Proc. Natl. Acad. Sci. 117(15), 8263 (2020).

4. Parker, A. G. et al. Holocene vegetation dynamics in the northeastern Rub' al-Khali desert, Arabian Peninsula: A phytolith, pollen and carbon isotope study. J. Quat. Sci. 19(7), 665-676 (2004).

5. Herold, M. \& Lohmann, G. Eemian tropical and subtropical African moisture transport: an isotope modelling study. Clim. Dyn. 33(7), 1075-1088 (2009)

6. Parton, A. et al. Middle-late Quaternary palaeoclimate variability from lake and wetland deposits in the Nefud Desert, Northern Arabia. Quat. Sci. Rev. 202, 78-97 (2018).

7. Clemens, S. et al. Forcing mechanisms of the Indian Ocean monsoon. Nature 353(6346), 720-725 (1991).

8. deMenocal, P. B. Plio-Pleistocene African climate. Science 270(5233), 53 (1995).

9. Burns, S. J. et al. Speleothem evidence from Oman for continental pluvial events during interglacial periods. Geology 29(7), 623-626 (2001).

10. Preusser, F., Radies, D. \& Matter, A. A 160,000-year record of dune development and atmospheric circulation in Southern Arabia. Science 296, 2018-2020 (2002).

11. Hoffmann, G. et al. Fluvio-lacustrine deposits reveal precipitation pattern in SE Arabia during early MIS 3. Quat. Int. 382, 145-153 (2015).

12. Burns, S. J. et al. Speleothem-based paleoclimate record from northern Oman. Geology 26(6), 499-502 (1998).

13. Rosenberg, T. M. et al. Late Pleistocene palaeolake in the interior of Oman: A potential key area for the dispersal of anatomically modern humans out-of-Africa?. J. Quat. Sci. 27(1), 13-16 (2012).

14. Rosenberg, T. M. et al. Humid periods in southern Arabia: Windows of opportunity for modern human dispersal. Geology 39(12), 1115-1118 (2011).

15. Atkinson, O. A. C. et al. Late Quaternary humidity and aridity dynamics in the northeast Rub' al-Khali, United Arab Emirates: Implications for early human dispersal and occupation of eastern Arabia. Quat. Int. 300, 292-301 (2013).

16. Stewart, J. R. \& Stringer, C. B. Human evolution out of Africa: The role of refugia and climate change. Science 335(6074), 1317-1321 (2012).

17. Parton, A. et al. Orbital-scale climate variability in Arabia as a potential motor for human dispersals. Quat. Int. 382, 82-97 (2015).

18. Nicholson, S. L. et al. Beyond arrows on a map: The dynamics of Homo sapiens dispersal and occupation of Arabia during Marine Isotope Stage 5. J. Anthropol. Archaeol. 62, 101269 (2021).

19. Groucutt, H. S. et al. Multiple hominin dispersals into Southwest Asia over the past 400,000 years. Nature https://doi.org/10.1038/ s41586-021-04289-2 (2021).

20. Groucutt, H. S. et al. Homo sapiens in Arabia by 85,000 years ago. Nat. Ecol. Evol. 2(5), 800-809 (2018).

21. Petraglia, M. D. et al. Middle Paleolithic occupation on a Marine Isotope Stage 5 lakeshore in the Nefud Desert, Saudi Arabia. Quat. Sci. Rev. 30(13-14), 1555-1559 (2011).

22. Groucutt, H. S. et al. Human occupation of the Arabian Empty Quarter during MIS 5: Evidence from Mundafan Al-Buhayrah, Saudi Arabia. Quat. Sci. Rev. 119, 116-135 (2015).

23. Armitage, S. J. et al. The Southern Route "Out of Africa": Evidence for an early expansion of modern humans into Arabia. Science 331(6016), 453-456 (2011).

24. Rose, J. I. et al. The Nubian Complex of Dhofar, Oman: An African Middle Stone Age industry in southern Arabia. PLoS ONE 6(11), e28239 (2011).

25. Petraglia, M. D. et al. Hominin Dispersal into the Nefud Desert and Middle Palaeolithic Settlement along the Jubbah Palaeolake, Northern Arabia. PLoS ONE 7(11), e49840 (2012).

26. Scerri, E. M. L. et al. The expansion of later Acheulean hominins into the Arabian Peninsula. Sci. Rep. 8(1), 17165 (2018).

27. Crassard, R. et al. Middle Palaeolithic occupations in central Saudi Arabia during MIS 5 and MIS 7: New insights on the origins of the peopling of Arabia. Archaeol. Anthropol. Sci. 11(7), 3101-3120 (2019).

28. Delagnes, A. et al. Inland human settlement in southern Arabia 55,000 years ago: New evidence from the Wadi Surdud Middle Paleolithic site complex, western Yemen. J. Hum. Evol. 63(3), 452-474 (2012).

29. Rose, J. I. et al. 30,000-year-old geometric microliths reveal glacial refugium in Dhofar, Southern Oman. J. Paleol. Archaeol. 2(3), 338-357 (2019).

30. Roberts, P. et al. Fossil herbivore stable isotopes reveal middle Pleistocene hominin palaeoenvironment in 'Green Arabia'. Nat. Ecol. Evol. 2, 1871-1878 (2018).

31. Hilbert, Y. H. et al. Epipalaeolithic occupation and palaeoenvironments of the southern Nefud desert, Saudi Arabia, during the Terminal Pleistocene and Early Holocene. J. Archaeol. Sci. 50, 460-474 (2014).

32. Hilbert, Y. H. et al. Archaeological evidence for indigenous human occupation of Southern Arabia at the Pleistocene/Holocene transition: The case of al-Hatab in Dhofar, Southern Oman. Paleorient 41(2), 31-49 (2015).

33. Rose, J. I. \& Petraglia, M. D. Tracking the origin and evolution of human populations in Arabia. In The Evolution of Human Populations in Arabia: Paleoenvironments, Prehistory and Genetics (eds Petraglia, M. D. \& Rose, J. I.) 1-12 (Springer, 2009).

34. Bretzke, K., Conard, N. J. \& Uerpmann, H.-P. Excavations at Jebel Faya: The FAY-NE1 shelter sequence. Proc. Semin. Arab. Stud. 44, 69-82 (2014). 
35. Goudie, A. S., Viles, H. A. \& Parker, A. G. Monitoring of rapid salt weathering in the central Namib Desert using limestone blocks. J. Arid Environ. 37(4), 581-598 (1997).

36. Bretzke, K. et al. The environmental context of Paleolithic settlement at Jebel Faya, Emirate Sharjah, UAE. Quat. Int. 300, 83-93 (2013).

37. Fleitmann, D. et al. Changing moisture sources over the last 330,000 years in Northern Oman from fluid-inclusion evidence in speleothems. Quat. Res. 60(2), 223-232 (2003).

38. Fleitmann, D. et al. Holocene and Pleistocene pluvial periods in Yemen, southern Arabia. Quatern. Sci. Rev. 30(7), 783-787 (2011).

39. Vaks, A. et al. Middle-Late Quaternary paleoclimate of northern margins of the Saharan-Arabian Desert: Reconstruction from speleothems of Negev Desert, Israel. Quat. Sci. Rev. 29(19), 2647-2662 (2010).

40. Goodall, T. M. The Geology and Geomorphology of the Sabkhat Matti Region (United Arab Emirates): A Modern Analogue for Ancient Desert Sediments of North-West Europe (University of Aberdeen, 1995).

41. Parton, A. et al. Alluvial fan records from southeast Arabia reveal multiple windows for human dispersal. Geology 43(4), 295-298 (2015).

42. Will, M., Conard, N. J. \& Tryon, A. C. Timing and trajectory of cultural evolution on the African continent 200,000-30,000 years ago. In Modern Human Origins and Dispersal (eds Sahle, Y. et al.) 25-72 (Kerns Verlag, 2019).

43. Leuschner, D. C. \& Sirocko, F. Orbital insolation forcing of the Indian Monsoon: A motor for global climate changes?. Palaeogeogr. Palaeoclimatol. Palaeoecol. 197(1), 83-95 (2003).

44. Parker, A. G. Pleistocene climate change in Arabia. In The Evolution of Human Populations in Arabia. Paleoenvironments Prehistory and Genetics (eds Petraglia, M. D. \& Rose, J. I.) 39-50 (Springer, 2009).

45. Parton, A. et al. An early MIS 3 pluvial phase in Southeast Arabia: Climatic and archaeological implications. Quat. Int. 300, 62-74 (2013).

46. Edgell, H. S. Arabian Deserts, Nature, Origin and Evolution (Springer, 2006).

47. Blechschmidt, I. et al. Monsoon triggered formation of Quaternary alluvial megafans in the interior of Oman. Geomorphology 110(3-4), 128-139 (2009).

48. Holzkämper, S. \& Mangini, A. U/Th dating of carbonate precipitates at the excavation site of Jebel al-Buhais. In The Natural Environment of Jebel al-Buhais: Past and Present (eds Uerpmann, H. P. et al.) 47-52 (Kerns Verlag, 2008).

49. Wood, W. W., Rizk, Z. S. \& Alsharhan, A. S. Timing of Recharge, and the Origin, Evolution, and Distribution of Solutes in a Hyperarid Aquifer System Water Resources Perspectives: Evaluation Management and Policy 295-312 (Elsevier, 2003).

50. Radies, D. et al. Eustatic and climatic controls on the development of the Wahiba Sand Sea, Sultanate of Oman. Sedimentology 51(6), 1359-1385 (2004).

51. Patzelt, A. et al. Studies in the flora of Arabia: XXXI. New rcords from the Sultanat of Oman. Edinb. J. Bot. 71(2), 161-180 (2014).

52. Feulner, G. R. Wadi fish of the UAE. Tribulus 8(3), 16-22 (1998).

53. Kaboth-Bahr, S. et al. Paleo-ENSO influence on African environments and early modern humans. Proc. Natl. Acad. Sci. 118, e2018277118. https://doi.org/10.1073/pnas.2018277118 (2021).

54. Heiri, O., Lotter, A. F. \& Lemcke, G. Loss on ignition as a method for estimating organic and carbonate content in sediments: Reproducibility and comparability of results. J. Paleolimnol. 25, 101-110 (2001).

55. Folk, R. L. \& Ward, W. C. Brazos River bar: A study in the significance of grain size parameters. J. Sediment. Petrol. 27, 3-26 (1957).

56. Lisiecki, L. E. \& Raymo, M. E. A Pliocene-Pleistocene stack of 57 globally distributed benthic d18O records. Paleoceanography 20 , 1003 (2005).

57. Jennings, R. P. et al. Human occupation of the northern Arabian interior during early Marine Isotope Stage 3. J. Quat. Sci. 31(8), e2920 (2016).

\section{Acknowledgements}

We thank the Sharjah Archaeology Authority for kind permission and their support of the field work at Jebel Faya. This work was further supported by the German Research Foundation through a grant to KB (DFG BR $5562 / 2-1)$ and the research center "The role of culture in early expansions of modern humans" (ROCEEH) of the Heidelberg Academy of Science and Humanities. We also thank the students and colleagues that have participated in the excavation.

\section{Author contributions}

K.B., S.J. designed research; K.B., F.P., C.M., G.P., K.R., S.J.U., A.P., A.G.P. performed research; K.B., F.P., A.G.P. analyzed data; and K.B., F.P., A.G.P. wrote the paper.

\section{Funding}

Open Access funding enabled and organized by Projekt DEAL.

\section{Competing interests}

The authors declare no competing interests.

\section{Additional information}

Supplementary Information The online version contains supplementary material available at https://doi.org/ 10.1038/s41598-022-05617-w.

Correspondence and requests for materials should be addressed to K.B.

Reprints and permissions information is available at www.nature.com/reprints.

Publisher's note Springer Nature remains neutral with regard to jurisdictional claims in published maps and institutional affiliations. 
(c) (i) Open Access This article is licensed under a Creative Commons Attribution 4.0 International cc) License, which permits use, sharing, adaptation, distribution and reproduction in any medium or format, as long as you give appropriate credit to the original author(s) and the source, provide a link to the Creative Commons licence, and indicate if changes were made. The images or other third party material in this article are included in the article's Creative Commons licence, unless indicated otherwise in a credit line to the material. If material is not included in the article's Creative Commons licence and your intended use is not permitted by statutory regulation or exceeds the permitted use, you will need to obtain permission directly from the copyright holder. To view a copy of this licence, visit http://creativecommons.org/licenses/by/4.0/.

(C) The Author(s) 2022 